\title{
Growth of a Pure and Single Phase Iron Sulfide (Pyrite) Thin Film by Electrochemical Deposition for Photovoltaic Applications
}

\author{
Emmanuel A. Botchway, Francis K. Ampong, Isaac Nkrumah, Francis K. Boakye, \\ Robert K. Nkum
}

Department of Physics, Kwame Nkrumah University of Science and Technology, Kumasi, Ghana

Email: inkrumah.sci@knust.edu.gh

How to cite this paper: Botchway, E.A. Ampong, F.K., Nkrumah, I., Boakye, F.K. and Nkum, R.K. (2019) Growth of a Pure and Single Phase Iron Sulfide (Pyrite) Thin Film by Electrochemical Deposition for Photovoltaic Applications. Open Journal of Applied Sciences, 9, 725-735.

https://doi.org/10.4236/ojapps.2019.99059

Received: August 9, 2019

Accepted: September 21, 2019

Published: September 24, 2019

Copyright $\odot 2019$ by author(s) and Scientific Research Publishing Inc. This work is licensed under the Creative Commons Attribution International License (CC BY 4.0).

http://creativecommons.org/licenses/by/4.0/

\begin{abstract}
Single phase iron pyrite $\left(\mathrm{FeS}_{2}\right)$ films have been successfully deposited on ITO-coated glass substrates using a 3-electrode electrochemical system with graphite as the counter electrode and $\mathrm{Ag} / \mathrm{AgCl}$ as the reference electrode. In this single-step electrodeposition, the FeS precursor thin film was directly electrodeposited on the conductive substrate from the electrolytic bath solution which contained $\mathrm{FeSO}_{4} \cdot 7 \mathrm{H}_{2} \mathrm{O}$ as an iron source, and $\mathrm{Na}_{2} \mathrm{~S}_{2} \mathrm{O}_{3} \cdot 5 \mathrm{H}_{2} \mathrm{O}$ as a sulfur source. The deposition was carried out potentiostatically at a constant potential of $-0.9 \mathrm{~V}$ vs. $\mathrm{Ag} / \mathrm{AgCl}$ at room temperature. The growth of the iron pyrite phase was achieved by annealing the as-deposited at $500^{\circ} \mathrm{C}$ for an hour in an ambient of sulfur to form the pyrite phase. For sulfurization, two different techniques, one using the Kipp's apparatus and a second, which involved heating elemental sulfur at $200^{\circ} \mathrm{C}$, were used for the production of the sulfur gas. X-ray diffraction analyses of the sulfurized films showed that both sulfurization techniques appeared to form the pyrite phase, however, the second method yielded films with maximum crystalline order and stoichiometry with no discernable impurity peaks. Optical absorption measurements revealed the existence of a direct transition with an estimated band gap of $1.75 \mathrm{eV}$. SEM micrograph showed a compact morphology with a rough surface made up of crystallites of irregular shapes and sizes with well-defined edges, covering the entire substrate. EDAX analysis of the film was consistent with the formation of $\mathrm{FeS}_{2}$ pyrite thin films.
\end{abstract}

\section{Keywords}

Iron Pyrite Films, Electrodeposition, Sulfurization, Solar Cell Materials

\section{Introduction}

Iron sulfide $\left(\mathrm{FeS}_{2}\right)$ pyrite phase, is a semiconductor material with remarkable 
properties suitable for solar cell applications. It is non-toxic and its constituents iron and sulfur are considered as elements which are highly abundant with low cost of extraction and processing [1]. This makes the large scale production of these materials quite feasible and cost-effective.

Pyrite is an absorber material that can be either an $n$ or $p$ type semiconductor depending on the type of dopant impurities [2]. Pyrite has electrical conductivity value which varies between 0.05 and $3.5(\Omega \cdot \mathrm{cm})^{-1}$ and carrier concentration which varies between $6.9 \times 10^{15}$ and $5.4 \times 10^{17} \mathrm{~cm}^{-3}$ [3]. As a result of its moderate band gap of $0.95 \mathrm{eV}$ and high optical absorption coefficient in the mid-infra-red range, Iron pyrite is considered as one of the most promising semiconductor materials to meet the pressing demand for low cost energy solutions. It has superior electrical properties with long minority carrier diffusion length of $\sim 0.1$ to $1.0 \mu \mathrm{m}$ and carrier mobility of about $360 \mathrm{~cm}^{2} \cdot \mathrm{V}^{-1} \cdot \mathrm{s}^{-1}$ [4]. The advantage of having a high absorption coefficient is of particular importance since only about $40 \mathrm{~nm}$ of pyrite is required to absorb $90 \%$ of the incident light [5].

Pyrite devices demonstrate elevated quantum efficiencies (often $>90 \%$ ) and photo-currents $\left(>40 \mathrm{~mA} \cdot \mathrm{cm}^{-2}\right)$ but small photo-voltages (typically $<200 \mathrm{mV}$, $\sim 20 \%$ of the band gap) [6]. The low photo-voltage value is liable for the restricted solar cell efficiency. Although theoretical investigation envisaged that greater than $18 \%$ efficiency should be achievable, in reality, pyrite based solar cells fabricated so far show evidence of less than $3 \%$ conversion efficiency [7]. The low photo-voltage is ascribed to bulk and surface vacancies that produce electronic states within the band gap [6]. The low efficiency is additionally thought to be caused by phase impurities like marcasite which is formed alongside pyrite when grown from aqueous solutions [8]. This mixed phase of $\mathrm{FeS}_{2}$ also deteriorates its photovoltaic performance.

Several techniques are available for the deposition of $\mathrm{FeS}_{2}$ thin films. Among these techniques, electrochemical deposition offers several advantages such as; the ability to control film thickness, composition, morphology, etc. by mainly controlling electrical parameters such as electrode voltage and current density, which are easily adjustable. The technique is simple and economical because of its use of low cost apparatus, low operating temperature, and negligible waste materials.

Electrochemical deposition of iron sulfide is usually carried out by a two-stage process using direct compound electrodeposition followed by sulfurization to obtain the pyrite phase.

Sulfurization plays a significant role in achieving single phase pyrite films, it involves thermal treatment of the thin film in a sulfur rich atmosphere. The main purpose of this is to increase the sulfur concentration of the films and in this case fill the sulfur vacancies usually found in FeS systems. The choice of sulfurization technique is crucial in determining the level of purity of the iron pyrite thin film. Different sulfurization techniques would produce iron pyrite films with different levels of purity. A few authors have studied and reported on 
various aspects of electrochemical deposition of iron sulfide thin films. Arico et al. [9] Studied some structural properties of electrodeposited iron sulfide thin films on Platinum substrates. Dong et al. [10] studied the effect of sulfurization temperature on the structure of Ferrous sulfide (FeS) thin films deposited on indium-tin oxide (ITO) substrates by electrochemical deposition, whilst Wang et al. [11] studied the effect of sulfurization time on the structure of electrodeposited iron sulfide thin films. Finally, Kawai et al. [12] studied the optimal conditions for the electrodeposition of iron sulfide thin films. Each of these authors used their own unique electrochemical factors such as $\mathrm{pH}$, electrolyte concentration, deposition potential, and temperature and deposition time. In this work, the use of graphite as the counter electrode, the deposition potential vs. $\mathrm{Ag} / \mathrm{AgCl}$, the $\mathrm{pH}$ of the electrolyte and concentrations $\mathrm{FeSO}_{4} \cdot 7 \mathrm{H}_{2} \mathrm{O}$ and $\mathrm{Na}_{2} \mathrm{~S}_{2} \mathrm{O}_{3} \cdot 5 \mathrm{H}_{2} \mathrm{O}$ used in preparing the electrolyte are unique to this work. We also devised our own technique for post deposition treatment of the as-deposited samples before sulfurization.

\section{Materials and Methods}

A conventional three-electrode setup consisting of an $\mathrm{Ag} / \mathrm{AgCl}$ reference electrode, a graphite plate as a counter electrode, and an ITO-coated glass substrateas a working electrode which was employed for electrodeposition.

The electrolyte solution contained $\mathrm{FeSO}_{4} \cdot 7 \mathrm{H}_{2} \mathrm{O}$ as an iron source, $\mathrm{Na}_{2} \mathrm{~S}_{2} \mathrm{O}_{3} \cdot 5 \mathrm{H}_{2} \mathrm{O}$ was used as a sulfur source, $\mathrm{H}_{2} \mathrm{SO}_{4}$ was used to adjust the $\mathrm{pH}$ during the electrodeposition process.

In preparation of the electrolyte, equal volumes $(\sim 40 \mathrm{~mL})$ of $0.24 \mathrm{M} \mathrm{Fe}$ $\mathrm{SO}_{4} \cdot 7 \mathrm{H}_{2} \mathrm{O}$ and $0.45 \mathrm{M} \mathrm{Na}_{2} \mathrm{~S}_{2} \mathrm{O}_{3} \cdot 5 \mathrm{H}_{2} \mathrm{O}$ were mixed together in a $100 \mathrm{ml}$ beaker. The resulting solution had a $\mathrm{pH}=3.73$ at room temperature. This $\mathrm{pH}$ was adjusted from 3.73 to 1.96 by adding a few drops of $2 \mathrm{M} \mathrm{H}_{2} \mathrm{SO}_{4}$, this was done to improve the adherence of the electrodeposits. The solution turned cloudy on adding the acid due to the formation of elemental sulfur. After about 20 to 30 minutes the electrolyte in the bath suddenly started to turn from cloudy to colorless as the sulfur precipitate had settled at the bottom of the beaker. Electrodeposition was carried out potentiostatically using an Echem ER466 potentiostat-galvanostat, at constant potential of $-0.9 \mathrm{~V}$ vs. $\mathrm{Ag} / \mathrm{AgCl}$ at room temperature $\left(30^{\circ} \mathrm{C} \pm 2^{\circ} \mathrm{C}\right)$. A growth time of $\sim 30$ minutes was ensured during electrodeposition. Beyond this time the films become too thick. A diagram of the experimental set-up is shown in Figure 1.

Most reports on the deposition of iron sulfide by a 3-electrode deposition, involve the use of saturated calomel electrode (SCE) as the reference electrode and platinum or gold as the counter electrode. However, in this work silver/silver chloride is used as the reference electrode and graphite plate as the counter electrode. The choice of the reference electrode affects the deposition potential. To the best of our knowledge not much work has been cited using this combination for a 3-electrode deposition of Iron sulfide thin films. In order to prevent the as-deposited films from oxidation, whilst being dried, the following technique 


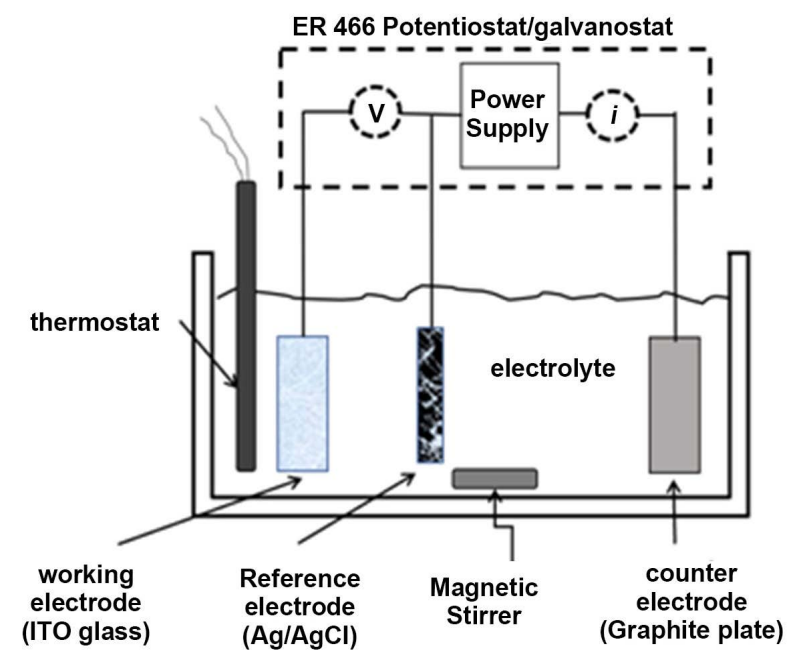

Figure 1. The three-electrode setup consisting of an $\mathrm{Ag} / \mathrm{AgCl}$ reference electrode, a graphite plate as a counter electrode, and an ITO-coated glass substrateas a working electrode.

was devised. A desiccator with freshly prepared drying agent was initially purged with Argon gas. The as-deposited sample was introduced into the desiccator which was connected to a vacuum pump to extract the argon and create a tight seal around the edge of the desiccator. After drying, the as-deposited films were annealed in a sulfur atmosphere at $500^{\circ} \mathrm{C}$ to form the pyrite phase. Two different techniques, described in the next section, were used to produce the sulfur gas for the sulfurization process. Emphasis is on comparing the quality of iron pyrite films produced by using the Kipp's apparatus to generate hydrogen sulfide gas for the sulfurization process and when elemental sulfur is heated at $200^{\circ} \mathrm{C}$ to form sulfur vapor for sulfurization.

\subsection{Sulfurization}

\section{Procedure 1: Production of $\mathrm{H}_{2} \mathrm{~S}$ Using Kipps Apparatus (Figure 2)}

In this procedure, sufficient amounts of iron sulfide lumps are placed in the central bulb of a Kipp's apparatus. $2 \mathrm{M}$ dilute sulfuric acid is added to the upper bulb with the tap open until the lower bulb is completely filled and the Iron Sulfide lumps covered with acid. The tap is then closed. The acid will react with iron Sulfide to produce hydrogen sulfide gas which fills up the middle bulb. The reaction equation is shown below

$$
\mathrm{FeS}+\mathrm{H}_{2} \mathrm{SO}_{4} \rightarrow \mathrm{FeSO}_{4}+\mathrm{H}_{2} \mathrm{~S}
$$

The hydrogen sulfide gas can be delivered for sulfurizing by opening the tap, as shown in Figure 1.

\section{Procedure 2: Using sulfur powder (Figure 3)}

In the procedure illustrated in Figure 3, elemental sulfur powder is used to produce the sulfur vapor. $0.5 \mathrm{~g}$ of sulfur powder was poured into a ceramic boat and together with the $\mathrm{FeS}_{2}$ sample, placed inside an enclosed borosilicate glass tube. Prior to this, the tube was flushed with Argon for 10 minutes to get rid of 


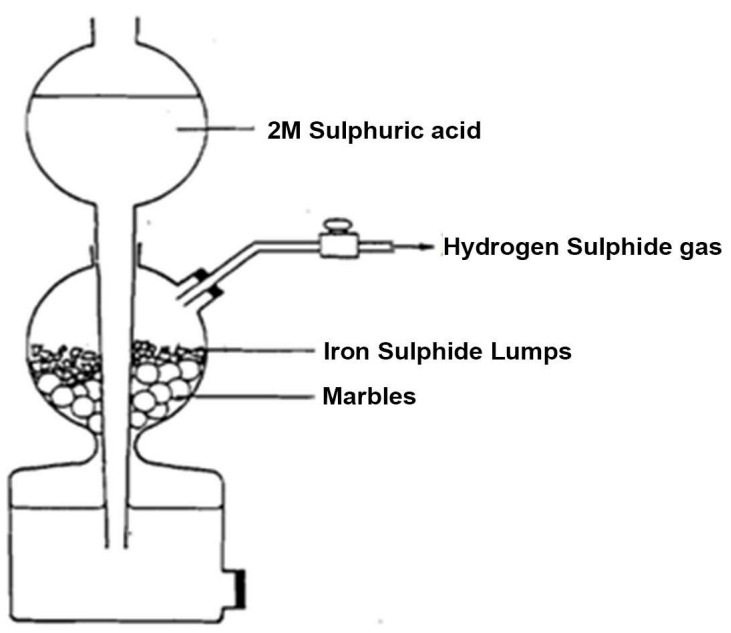

Figure 2. Kipp's apparatus.

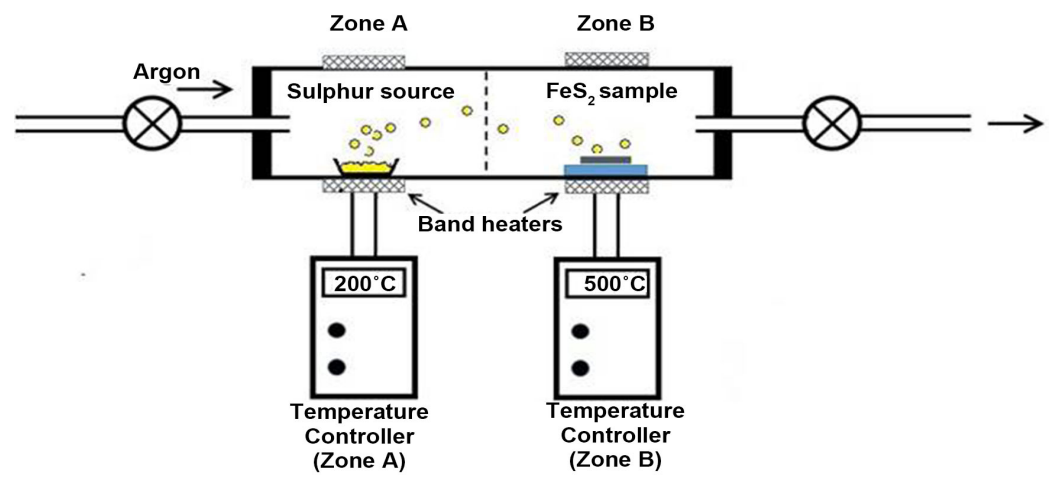

Figure 3. Schematic illustration of the two-heating-zone borosilicate-tube furnace.

any oxygen. The temperature of the sample heating zone was raised and held at $500^{\circ} \mathrm{C}$ for 30 minutes. The Sulfur zone was heated and maintained at $200^{\circ} \mathrm{C}$. Having sulfur vapor in the tube throughout the process is very important to ensure the supplement and incorporation of sulfur into the film during the annealing process. An Argon flux was used to carry the sulfur vapor inside the tube. After the sulfurization process, the furnace was allowed to cool down naturally by turning down the heat whilst under the flow of argon.

\subsection{Characterization}

Structural analysis was first carried out to determine which sulfurization technique was suitable for achieving single phase pyrite films. The pyrite film with the highest purity score was then characterized further by optical absorbance measurements, scanning electron microscopy (SEM) and energy dispersive $\mathrm{X}$-ray (EDX) analysis.

\section{Results and Discussions}

\subsection{XRD Analysis}

The XRD data was obtained by a PANalytical Empyrean Series 2 powder X-ray 
diffractometer with Cu-ka radiation $(1.5406 \AA)$ in the range of $2 \theta=\left(10^{\circ}-90^{\circ}\right)$. The machine was operated at $40 \mathrm{~mA}$ and $45 \mathrm{kV}$ for phase analysis using the Bragg-Brentano geometry. Total analysis time per samples was around $35 \mathrm{mi}$ nutes for a $2 \theta$ scan step of $0.06^{\circ}$. The X-ray data was analyzed using the HighScore Plus software.

The X-ray diffractogram shown in Figures 4(a)-(c) compares the composition of the as-deposited FeS precursor thin film and films sulfurized by the two different procedures described.

Figure 4(a) shows the diffraction pattern obtained after the direct compound electrodeposition of $\mathrm{FeS}_{2}$. The pattern of prominent peaks in the diffractogram was matched to FeS (JCPDS Card No. 65- 9124) and $\mathrm{Fe}_{1-\mathrm{x}} \mathrm{S}$ (JCPDS Card No. 29-0726) compounds. There were no peaks corresponding to the $\mathrm{FeS}_{2}$ pyrite phase.

Figure 4(b) had a significant number of peaks indexed to the $\mathrm{FeS}_{2}$ pyrite phase (JCPDS No. 65-3321). A few peaks labelled as ' $x$ ' were matched to impurity phases such as FeS (JCPDS Card No.65- 9124) and $\mathrm{Fe}_{1-\mathrm{x}} \mathrm{S}$ (JCPDS Card No. 29-0726). The score for the pyrite phase is 70 as shown in the pattern list in $\mathrm{Ta}$ ble 1.

The different assigned peaks shown in Figure 4(c) were made by comparing with JCPDS standards and they were a perfect match to $\mathrm{FeS}_{2}$ pyrite phase (JCPDS No. 65-3321). These crystalline peaks occurring at $2 \theta=28.4956^{\circ}$, $33.0393^{\circ}, 37.07443^{\circ}, 40.7648^{\circ}, 47.4354^{\circ}, 56.2717^{\circ}, 59.0751^{\circ}, 61.6613^{\circ}, 64.2344^{\circ}$ and $79.0545^{\circ}$ correspond to reflections from the (111), (200), (210), (211), (220),
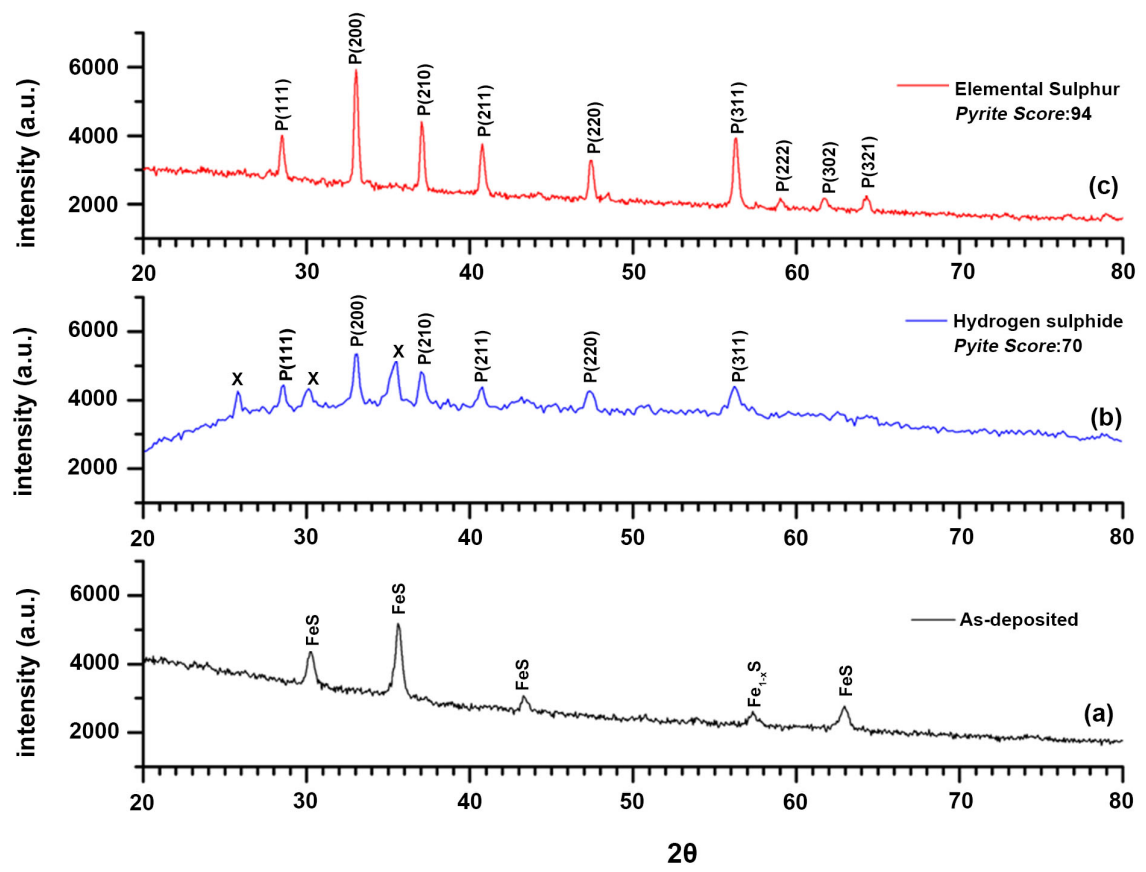

Figure 4. (a) The diffraction pattern of the as-deposited film. (b) The diffraction pattern obtained with the films sulfurized by the technique described in procedure 1, (c) The diffraction pattern obtained from films sulfurized by the technique described in procedure 2 . 
Table 1. Pattern List for procedure 1.

\begin{tabular}{|c|c|c|c|c|c|c|}
\hline$\underline{\text { Visible }}$ & $\underline{\text { Ref.Code }}$ & $\underline{\text { Score }}$ & $\frac{\text { Compound }}{\text { Name }}$ & Displ. [ [ $2 \mathrm{Th}]$ & $\underline{\text { Scale Fac. }}$ & Chem. Formula \\
\hline * & 01-071-4918 & 37 & Iron Oxide & 0.000 & 0.829 & $\mathrm{Fe}_{3} \mathrm{O}_{4}$ \\
\hline * & 01-083-0078 & 22 & $\begin{array}{c}\text { Iron Sulfate } \\
\text { Hydrate }\end{array}$ & 0.000 & 0.691 & $\mathrm{Fe}\left(\mathrm{SO}_{4}\right)\left(\mathrm{H}_{2} \mathrm{O}\right)$ \\
\hline * & $00-042-1340$ & 70 & Iron Sulfide & 0.000 & 1.012 & $\mathrm{Fe} \mathrm{S}_{2}$ \\
\hline
\end{tabular}

(311), (222), (023), (321) and (420) planes, respectively. The absence of any impurity peaks is a clear indication of the high purity of the sample. The score for the pyrite phase is 94 as shown in the pattern list in Table 2.

It is clear from the diffractograms and the pattern list in Table 1 and Table 2 that the sulfurization technique described in procedure 2 , that is, by using sulfur vapor is preferable for achieving single phase pyrite films.

Table 1 and Table 2 are the qualitative information on the relative amounts of different phases detected in the thin films and their corresponding structure, produced by the High Score Plus software.

The crystal structure of pyrite is cubic [13]. The lattice parameter " $a$ " was estimated from the equation below

$$
\frac{1}{d^{2}}=\frac{h^{2}+k^{2}+l^{2}}{a^{2}}
$$

where $d$ and $h, k$ and $l$ are inter-planar spacing and Millar indices respectively.

The value obtained for the lattice parameters was $5.42256 \AA$. This result is close to the reported value for pyrite.

The average grain size determined by Scherrer's formula was $31.9861 \mathrm{~nm}$ which is close to values reported by [14] [15].

\subsection{Scanning Electron Microscopy (SEM)}

Scanning electron microscopy (SEM) images and energy dispersive X-ray (EDX) analyses were obtained using a Phenom instrument with nominal electron beam voltages of $15 \mathrm{kV}$ respectively.

The SEM micrograph of $\mathrm{FeS}_{2}$ (pyrite phase) thin film is shown in Figure 5. The micrograph shows a compact morphology with a rough surface made up of crystallites of irregular shapes and sizes with well-defined edges, covering the entire substrate.

\subsection{Compositional Analysis by Energy Dispersive X-Ray Spectroscopy (EDX)}

Figure 6 shows the EDAX spectrum and elemental composition of the films. The EDAX analysis of the film is consistent with the formation of $\mathrm{FeS}_{2}$. From the table (inset), it can be observed that the films have good stoichiometry.

\subsection{Determination of the Optical Band Gap}

A Cecil CE7500 series double beam UV-Visible spectrometer operating in the 
Table 2. Pattern List for procedure 2.

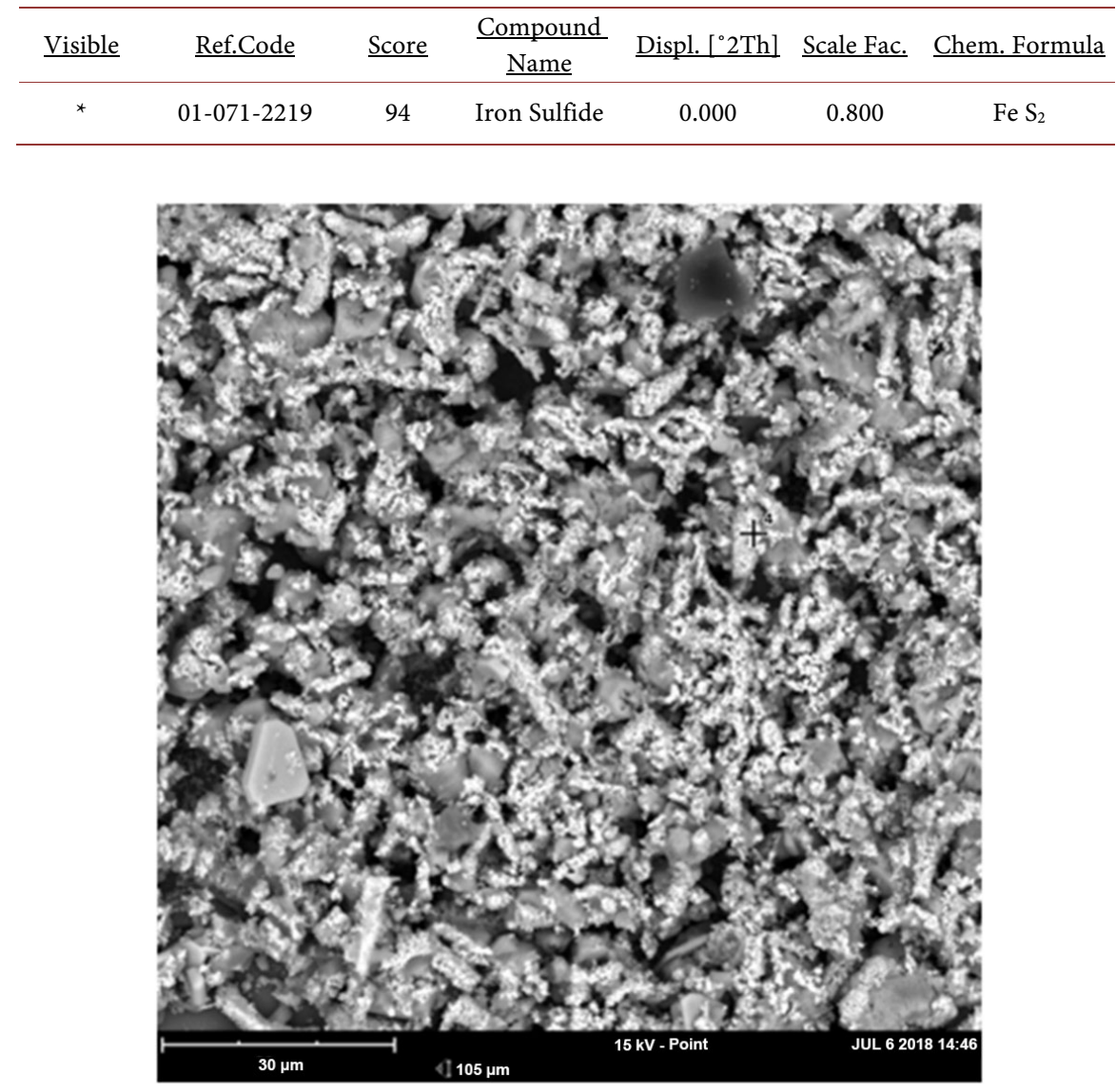

Figure 5. SEM micrograph of the $\mathrm{FeS}_{2}$ thin film.

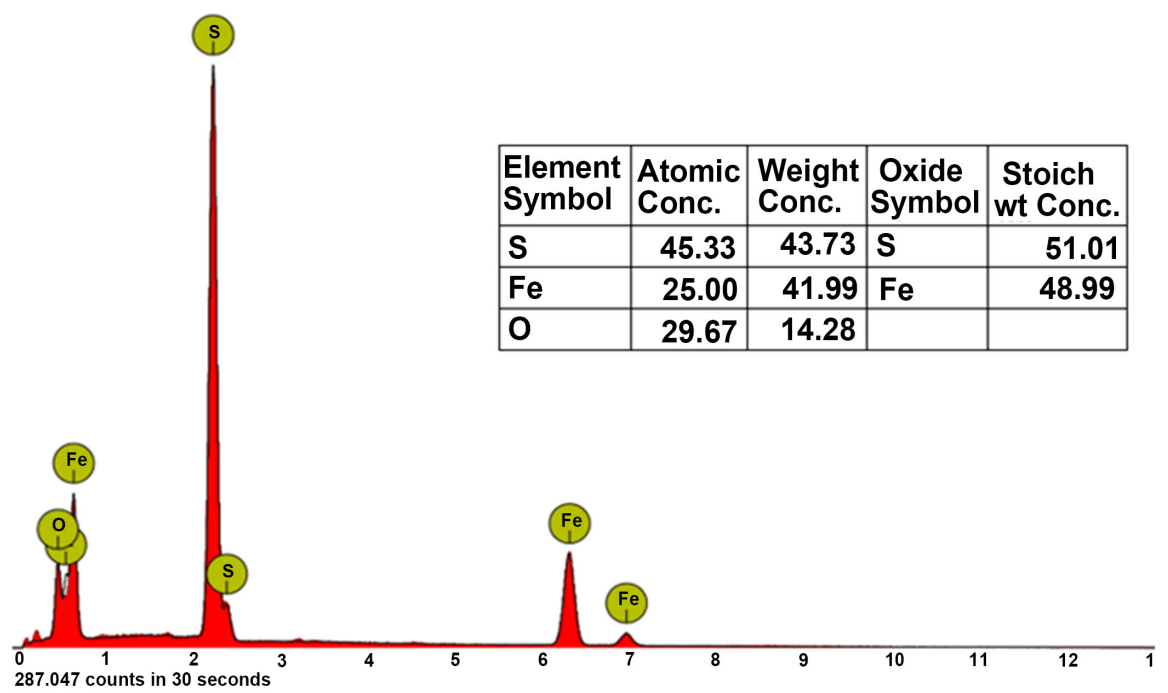

Figure 6. EDX spectrum of $\mathrm{FeS}_{2}$ thin film.

wavelength range of $190 \mathrm{~nm}$ to $1100 \mathrm{~nm}$, was used for optical absorbance measurements. Alternatively, the energy band gap and type of electronic transition can be estimated with the Stern (1963) equation [16]. 


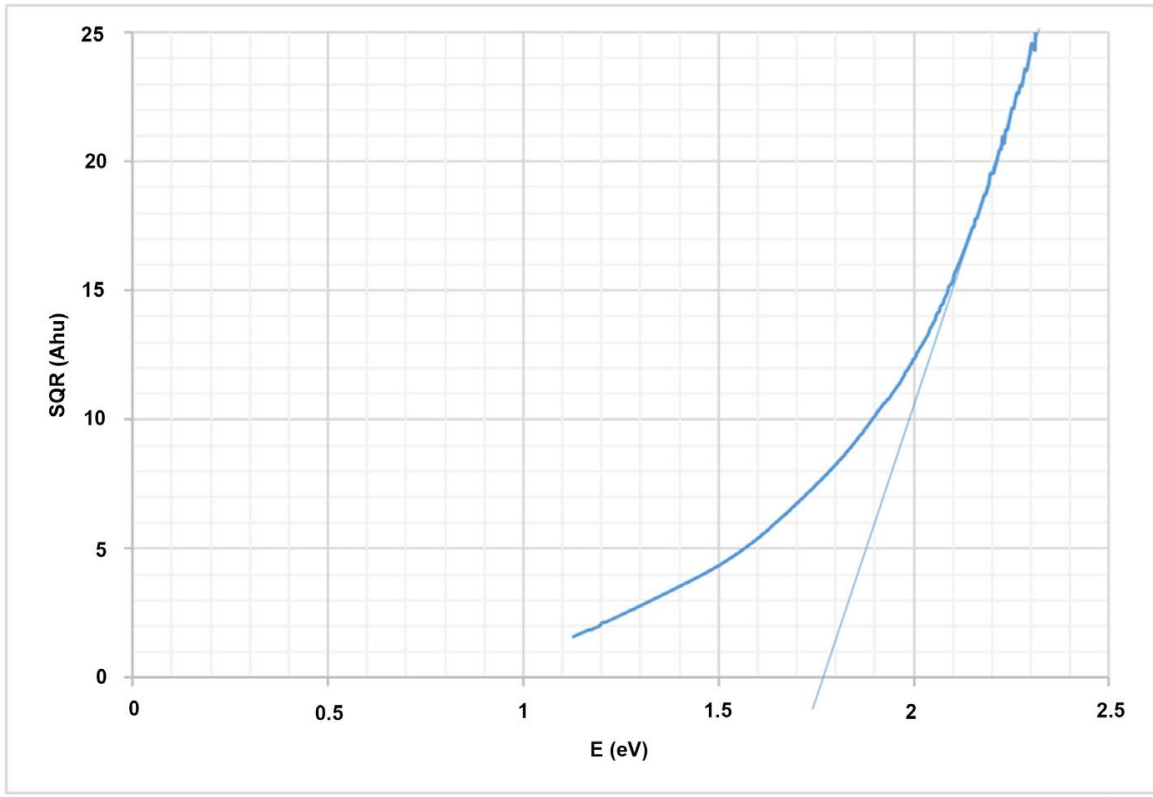

Figure 7. A plot of square of product absorbance, A and photon energy, $h v\left((A h v)^{2}\right)$ vs photon energy, $h v$ for $\mathrm{FeS}_{2}$ thin film.

$$
A=\frac{\left[k\left(h v-E_{g}\right)\right]^{n / 2}}{h v}
$$

where $v$ is the frequency, $h$ is the Planck's constant, $k$ equals a constant while the value of $n$ is either 1 for direct transitions and 4 for indirect transitions, respectively. The band gap energy is obtained by plotting a line of best fit on the $(A h v)^{2 / n}$ versus $h v$ graph and extrapolating the line to intersect the energy axis at $(A h v)^{2 / n}=0$.

Figure 7 shows the band gap of the $\mathrm{FeS}_{2}$ thin film. The linear nature of the plot confirms the presence of a direct transition. The estimated band gap for the $\mathrm{FeS}_{2}$ thin film is $1.75 \mathrm{eV}$. This significant blue shift $(0.85 \mathrm{eV})$ of the band gap from the bulk value of $0.95 \mathrm{eV}$, could be attributed to quantum size effect induced by the Nano crystallites in the film [17] [18].

\section{Conclusion}

Single phase iron pyrite $\left(\mathrm{FeS}_{2}\right)$ films have been successfully deposited on ITO-coated glass substrates using a 3-stage electrochemical system followed by sulfurization. X-ray diffraction analyses confirmed that the sulfurization technique which involved heating elemental sulfur at $200^{\circ} \mathrm{C}$ to generate sulfur gas, yielded films with maximum crystalline order and stoichiometry. There were no discernable peaks corresponding to impurity phases. EDAX analysis of the film was consistent with the formation of $\mathrm{FeS}_{2}$. SEM micrograph of the $\mathrm{FeS}_{2}$ pyrite films showed a compact morphology with a rough surface made up of crystallites of irregular shapes and sizes with well-defined edges, covering the entire substrate. Optical absorption measurements revealed the existence of a direct transition with an estimated band gap of $1.75 \mathrm{eV}$. All the results from the cha- 
racterization techniques indicate that the synthesis process used in this work, produced single phase iron pyrite $\left(\mathrm{FeS}_{2}\right)$ thin films, which can be used as absorber materials in solar cells. Future work would include further characterization by techniques such as Photoluminescence, and I-V measurements, and also measuring the variation of the concentration of $\mathrm{FeSO}_{4} \cdot 7 \mathrm{H}_{2} \mathrm{O}$ with electrical conductivity.

\section{Acknowledgements}

The authors wish to acknowledge the Department of Physics, and the Department of Earth science, both in the University of Ghana, Legon, for the use of the $\mathrm{X}$-ray diffraction equipment, scanning electron microscope and the energy dispersive $\mathrm{x}$-ray machine.

\section{Conflicts of Interest}

The authors declare no conflicts of interest regarding the publication of this paper.

\section{References}

[1] Wadia, C., Alivisatos, A.P. and Kammen, D.M. (2009) Materials Availability Expands the Opportunity for Large-Scale Photovoltaics Deployment. Environmental Science \& Technology, 43, 2072-2077. https://doi.org/10.1021/es8019534

[2] Spagnoli, D., Refson, K., Wright, K. and Gale, J.D. (2010) Density Functional Theory Study of the Relative Stability of the Iron Disulfide Polymorphs Pyrite and Marcasite. Physical Review B-Condensed Matter and Materials Physics, 81, Article ID: 094106. https://doi.org/10.1103/PhysRevB.81.094106

[3] Schieck, R., Hartmann, A., Fiechter, S., Könenkamo, R. and Wetzel, H. (1990) Electrical Properties of Natural and Synthetic Pyrite $\left(\mathrm{FeS}_{2}\right)$ Crystals. Journal of Materials Research, 5, 1567-1572. https://doi.org/10.1557/JMR.1990.1567

[4] Cabán-Acevedo, M., Faber, M.S., Tan, Y., Hamers, R.J. and Jin, S. (2012) Synthesis and Properties of Semiconducting Iron Pyrite $\left(\mathrm{FeS}_{2}\right)$ Nanowires. Nano Letters, 12, 1977-1982. https://doi.org/10.1021/nl2045364

[5] Hibberd, C.J., Chassaing, E., Liu, W., Mitzi, D.B., Lincot, D. and Tiwari, A.N. (2010) Non-Vacuum Methods for Formation of $\mathrm{Cu}(\mathrm{In}, \mathrm{Ga})(\mathrm{Se}, \mathrm{S})_{2}$ Thin Film Photovoltaic Absorbers. Progress in Photovoltaics. Research and Applications, 18, 434-452. https://doi.org/10.1002/pip.914

[6] Seefeld, S., Law, M., Puthussery, J., Berry, N. and Gibbs, M. (2010) Colloidal Iron Pyrite $\left(\mathrm{FeS}_{2}\right)$ Nanocrystal Inks for Thin-Film Photovoltaics. Journal of the American Chemical Society, 133, 716-719. https://doi.org/10.1021/ja1096368

[7] Kment, S., Kmentova, H., Sarkar, A., Soukup, R.J., Ianno, N.J., Sekora, D., Olejnicek, J., Ksirova, P., Krysa, J., Remes, Z. and Hubicka, Z. (2014) Epoxy Catalyzed Sol-Gel Method for Pinhole-Free Pyrite $\mathrm{FeS}_{2}$ Thin Films. Journal of Alloys and Compounds, 607, 169-176. https://doi.org/10.1016/j.jallcom.2014.04.060

[8] Thomas, B., Cibik, T., Hopfner, D.K., Ehlers, G., Fiechter, S. and Ellmer, K. (1998) Formation of Secondary Iron-Sulphur Phases in Growth of $\mathrm{FeS}_{2}$ Thin Films by MOCVD. Journal of Materials Science: Materials in Electronics, 9, 61-64. https://doi.org/10.1023/A:1008888801424 
[9] Arico, A.S., Antonucci, V., Antonucci, P.L., Modica, E., Ferrara, S. and Giordano, N. (1992) Electrodeposition and Characterization of Iron Sulphide Thin Films. Materials Letters, 13, 12-17. https://doi.org/10.1016/0167-577X(92)90169-K

[10] Dong, Y.Z., Zheng, Y.F., Zhang, X.G., Duan, H., Sun, Y.F. and Chen, Y.H. (2005) $\mathrm{FeS}_{2}$ (Pyrite) Electrodeposition Thin Films and Study of Growth Mechanism. Science in China Series E Technological Sciences, 48, 601. https://doi.org/10.1360/102004-32

[11] Wang, X., Wang, G., Chen, J., Zhu, X., Tian, J., Jiang, C., Zhang, Y., Liu, X. and Wang, R. (2013) Pyrite Thin Films Prepared for Thermal Batteries via Sulfuring Electrodeposited Iron Sulfide Films: Structure and Physical Properties. Materials Letters, 110, 144-147. https://doi.org/10.1016/j.matlet.2013.07.107

[12] Kawai, S., Yamazaki, R., Sobue, S., Okuno, E. and Ichimura, M. (2014) Electrochemical Deposition of Iron Sulfide Thin Films and Heterojunction Diodes with Zinc Oxide. APL Materials, 2, Article ID: 032110. https://doi.org/10.1063/1.4869035

[13] Kao, C.T., Shi, J., Bin, Lee, H.W., Cheng, F.C., Liu, H.H., Lee, M.W., Chan, C.C., Huang, C.W., Lin, H.S., Wu, P.F., Chen, C.Y., Kao, M.C., Young, S.L. and Lin, C.L. (2016) Temperature-Dependent Effects of $\mathrm{FeS}_{2}$ Thin Film Synthesized by Thermochemical Spraying: An Optical and Physicochemical Investigation. Journal of Thermal Spray Technology, 25, 580-586. https://doi.org/10.1007/s11666-016-0379-7

[14] Huang, L., Liu, Y. and Meng, L. (2009) Pyrite Films Grown by Sulfurizing Precursive Iron of Different Crystallizing Status. Journal of Materials Science and Technology, 25, 237-241.

[15] Srivastava, A., Parkash, O., Kumar, D. and Maiti, P. (2018) Structural and Dielectric Properties of Lanthanum Doped $\mathrm{CaCu}_{3} \mathrm{Ti}_{4} \mathrm{O}_{12}$ for Capacitor Application. American Journal of Materials Synthesis and Processing, 2, 90-93.

[16] Anuar, K., Tan, W., Jelas, M., Ho, S.M. and Gwee, S.Y. (2010) Effects of Deposition Period on the Properties of $\mathrm{FeS}_{2}$ Thin Films by Chemical Bath Deposition Method. Thammasat International Journal of Science and Technology, 15, 64.

[17] Kotadiya, N.B., Kothari, A.J., Tiwari, D. and Chaudhuri, T.K. (2012) Photoconducting Nanocrystalline Lead Sulphide Thin Films Obtained by Chemical Bath Deposition. Applied Physics A: Materials Science and Processing, 108, 819-824. https://doi.org/10.1007/s00339-012-6974-7

[18] Tohidi, T., Jamshidi-Ghaleh, K., Namdar, A. and Abdi-Ghaleh, R. (2014) Comparative Studies on the Structural, Morphological, Optical, and Electrical Properties of Nanocrystalline PbS Thin Films Grown by Chemical Bath Deposition Using Two Different Bath Compositions. Materials Science in Semiconductor Processing, 25, 197-206. https://doi.org/10.1016/j.mssp.2013.11.028 